\title{
Study on the Inheritance and Future-Generation Transmission of Filial Piety and Respect for the Elderly Culture of the New Generation of Preschool Education Undergraduates in Shanghai
}

\author{
Haiyan Hao* \\ Philosophy Department, Beijing Normal University, Beijing, China
}

*Corresponding Author: Haiyan Hao, Philosophy Department, Beijing Normal University, Beijing, China

\begin{abstract}
Preschool education undergraduates are future preschool teachers, who serve as inheritors and disseminators of the filial piety and respect for the elderly culture. The improvement of their corresponding humanistic quality and educational skills will help them better design and implement related educational activities, thus ultimately promoting the sound development of preschool children. In this study, the internationally mainstream education science research method (mixed methods), which is a combination of indepth qualitative analysis and quantitative data statistics, is employed to examine the preschool education students' cultural inheritance and education view of filial piety culture from multiple perspectives and dimensions. The results of the study show that the new generation of preschool education students in Shanghai actively recognize their role as inheritors of traditional culture, including the filial piety and respect for the elderly culture, and regard the cultural dissemination as their mission. On this basis, the research group puts forward policy suggestions.
\end{abstract}

Keywords: filial piety and respect for the elderly culture, culture inheritance, teachers' quality

\section{Problem Presentation and Research Significance}

China is the country with the largest number of elderly people, accounting for about one-fifth of the total number of older people in the world. As the first city in China to enter an aging society, Shanghai has entered a stage of deep aging. By the end of 2014, the registered elderly population in Shanghai had exceeded 4 million for the first time, and it is expected to exceed 5 million by the middle of 13th Five-Year plan.[1] With the rapid economic development and the continuous improvement of the social security system, the material support has gradually improved. However, with the acceleration of China's population mobility and the change of family structure, the lack of spiritual comfort and mental health problems existing in the elderly in urban and rural areas have gradually become apparent. In response to the deep aging population structure and growing demand for elderly care services, it is planned that by 2020 , Shanghai will build "a 'five in one' comprehensive social old-age service system featuring service supply, social security, policy support, demand assessment, and industry supervision", as well as old-age friendly city and elderly livable communities.[1]

"Filial piety" is the oldest, most basic, most important and most far-reaching traditional ethical concept in Chinese culture. Xi Jinping pointed out: respecting and loving the elderly is the traditional virtue of the Chinese nation. [2]In the context of the prominent social problems of deep aging in Shanghai and the plight of cultural inheritance of filial piety and respect for the elderly, this research aims to investigate and analyze the current recognition and intention of preschool education undergraduates for the inheritance (by themselves) and reinheritance (towards preschool children) of traditional filial piety culture with the new generation of future preschool teachers who have special significance to traditional culture inheritance as research object, and finally, based on the findings of empirical study and successful experience of foreign countries, put forward policy suggestions.

This research has both theoretical and practical value:

- It is of great significance to understand the current situation and influencing factors of contemporary college students' cultural inheritance and innovation for the promotion of "cultural soft power" of the state. 
- In this study, the internationally mainstream education science research method (mixed methods), which is a combination of in-depth qualitative analysis and quantitative data statistics, is employed to examine the preschool education students' cultural inheritance and education view of filial piety culture from multiple perspectives and dimensions.

- Children and youth are the future of society. The good inheritance and innovation of the filial piety and respect for the elderly culture have a practical meaning for Shanghai to resolve the problem of in-depth ageing and establish an elderly-friendly city and a livable community for the elderly in 2020;

- Understanding the current status of college students' ideological trends and educational concepts facilitates colleges' ideological and political work of students and contributes to the formulation and improvement of the training programs for preschool education professionals and in-service teachers.

- Preschool education undergraduates are future preschool teachers, who serve as the inheritors and the disseminators of filial piety and respect for the elderly culture. The improvement of their corresponding humanistic quality and educational skills will help them better design and implement related educational activities, thus ultimately promoting the sound development of preschool children.

\section{CONCEPT DEFINITION AND LITERATURE REVIEW}

When it comes to literature collection, the project members retrieved the CNKI database and library resources of our Xianda College and collected online and offline materials from neighboring Shanghai International Studies University to which our college is affiliated.

\subsection{Definition of the Basic Concepts Related to the Study}

There are many researches on filial piety (loving and respecting elders) culture, but the definition of its connotation is not exactly the same. According to the Doctrine of the Mean, Confucius once said: "Benevolence (ren) is human virtue, and loving one's parents and relatives (qinqin) is the first." "qinqin", the first "qin" means "love" and according to Annotations of Classic of Filial Piety, "Being benevolent is qin"; The second "qin" means parents and relatives. The spirit of "benevolence" is what human beings have in nature, and the love of their parents and relatives is the most fundamental. Tang Yijie believes that the core concept of "filial piety", "qinqin" (love one's own parents and relatives), is not only a family ethic also bears certain "universal value". "Loving one's parents and relatives" can be extended to "being benevolent to people" and then to "cherishing everything in the world". The social meaning of this expansion process should be valued by us. [3]

\subsection{The Educational Carrier Function of the Festival Activities}

As one of carriers of filial piety culture, festivals can effectively create an atmosphere of filial piety culture in society. Many traditional Chinese and foreign festivals take filial piety culture as their core value and present it in a cyclical manner. In the kindergarten, festival and folklore education activities can help children have a deep understanding of their hometown folk culture and cultivate their feelings of loving their motherland and hometown and respecting their elders. [4] For example, the festival activities that can be organically integrated into the theme of kindergarten education include the Lantern Festival (Lunar January $15^{\text {th }}$ ), New Year's Day (January $1^{\text {st }}$ ), Tomb Sweeping Day (April $5^{\text {th }}$ ), International Family Day (May $15^{\text {th }}$ ) and Mother's Day, etc.

\subsection{The International Visions of Filial Piety (Love And Respect for Elders) Culture}

China's Hong Kong, Taiwan, and Southeast Asia, including Singapore, Japan, and South Korea, etc. are deeply influenced by Confucian culture, where filial piety culture has a profound influence on social culture, policies, laws, and education services. In the whole society, filial piety education has received extensive attention from leaders and all members of the society. It regards respecting elderly, loving children, and helping each other as part of ethics, making young people of the whole society able to consciously observe filial piety and form related code of conduct. It also pays attention to etiquette education and carries out a series of activities to effectively publicize the social trends of love and respect for the elderly. In addition to the legal regulation, media measures are taken to avoid the unethical behavior of abandoning one's parents, such as public opinion condemnation with media 
exposure. [5]

Based on what mentioned above, the basic viewpoints of this study are as follows:

- The traditional culture of Chinese nation is extensive and profound. It plays a positive role in national moral spirit, value and conduct code promotion to inherit the excellent traditional culture. And university is an important platform and carrier for the heritance and innovation of traditional culture.

- Filial piety is Chinese traditional virtue and foundation for human morality. However, there are certain hypocrisy and human nature oppression and destruction elements in traditional filial piety which need to be abandoned.

- As the foundational stage of primary education, early childhood education has great national significance and educational value in the inheritance of national culture .In the preschool period, we advocate filial piety concepts which are consistent with the traditional culture of love and respect for elders but more suitable for young children and at the same time in line with international relevant ideas.

\section{RESEARCH IDEAS AND METHODS}

This research employs the mixed methods which combine qualitative analysis and quantitative statistics. It investigated the preschool education undergraduates, analyzed their current acceptance of inheriting our traditional filial piety culture and willingness to pass on to the future preschool children, and finally proposed policy suggestion with reference of related concepts and measures abroad. In the research, a comprehensive research method such as questionnaire survey and individual interviews are used.

The questionnaire consists of 28 multiple-choice questions (including questions with single one correct answer and questions with more than one correct answers), which involves the basic information of the investigation objectives, their cognition and acceptance of the traditional culture mainly the filial piety culture and their willingness to pass on the culture to their future education objectives, the preschool children. After deliberation, the initial version of questionnaires were first tested in small scope, and after revision, the final version was formed. The survey targets are preschool education undergraduates in Shanghai from Xianda College of Economics and Humanities of Shanghai International Studies University, Shanghai Normal University, Tianhua College of Shanghai Normal University, and East China Normal University, etc. The total number of valid questionnaires is 534. At the same time, in one of the colleges, the research group invited 10 students from each grade to conduct one-on-one interviews on a voluntary basis. Among them, there were 3 in grade one, 2 in grade two, 3 in grade three and 2 in grade four. Each interview lasts about 15 to 30 minutes. With consent of the interviewees, each interview was recorded.

In terms of research means, this study makes full use of the new media technology, conducting surveys through the WeChat platform and using the mobile phone app software "Questionnaire Star" to design and issue questionnaires to ensure effective and timely recovery. The research group obtained questionnaire feedback from the preschool education students of Xianda College of Shanghai International Studies University with advantageous communication channel between tutors and students and made targeted investigation with preschool education undergraduates of East China Normal University and Shanghai Normal University through interpersonal relationships of the faculty.

The study includes five steps:

- Questionnaire formation and revision. On the basis of the existing project application report, further literature search, research group discussion and small-scale tests are carried out so as to revise the questionnaire and refine the specific implementation steps such as questionnaire issue and recovery and statistical analysis; and research object contact and survey scope determination are conducted at the same time.

- Questionnaire issue. Conduct online investigation by distributing questionnaires to college students through WeChat; at the same time, make individual interviews.

- Data analysis. Collect the questionnaires, conduct data statistics, and make qualitative analysis of 
interview records (field notes and recording).

- Report writing. Based on the findings of the survey and interviews and research and experience at home and abroad, propose policy suggestions and write research report.

- Report submission. Through internal discussion of the research group and consultation with invited experts, the report is revised and submitted before the deadline.

\subsection{Survey Results and Analysis}

The data come from the online questionnaire survey and one-on-one personal interviews. Correspondingly, the result analysis (quantitative and qualitative) is composed of two parts.

- Basic information of the survey respondents. The schools that participated in this survey include several state and non-state universities and colleges in Shanghai area that have preschool education major. The composition of the survey respondents is proportional to the practical gender percentage of the preschool education classes, where female students are the majority $(93.26 \%)$.

- Current preschool education students' cognition and acceptance of the traditional filial piety culture. It involves the preschool education students' cognition of Chinese traditional culture especially the filial piety culture, knowledge of the cultivation methods of the filial piety culture, family influence on the filial piety culture cognition and the performance ways of filial piety. Illustrate from following five aspects:

\subsection{Cognition of Chinese Traditional Culture}

According to the survey data, the new generation of preschool education students are interested in the traditional culture (66.48\% are very or relatively interested). The main channels for them to get to know the traditional culture(see Table1): television(80.71\%), movies (73.03\%), books $(64.79 \%)$, new media $(59.18 \%)$, newspaper and journals $(40.64 \%)$, broadcasting $(26.4 \%)$ and others(including family influence, school study, travel, field visit or folk culture activity participation, etc, $23.03 \%$,see Table1). Traditional media such as the television, movies and books are still the major channels. In terms of new media, the major internet channels are microblogs or blogs $(77.9 \%)$, and then the instant chatting APPs such as Wechat and QQ(68.91\%), portals (40.26\%), forums (23.22\%) and others (including video barrage websites such as Bilibili, video software, internet novels and micro classes, etc. $19.85 \%)$

Table1: Main channels for undergraduates to know traditional culture

\begin{tabular}{|c|c|c|}
\hline options & number & ratio \\
\hline broadcasting & 141 & $26.4 \%$ \\
\hline TV & 431 & $80.71 \%$ \\
\hline Movies & 390 & $73.03 \%$ \\
\hline Books & 346 & $64.79 \%$ \\
\hline Newspapers and Magazines & 217 & $40.64 \%$ \\
\hline New media & 316 & $59.18 \%$ \\
\hline Others(please write) & 123 & $23.03 \%$ \\
\hline Valid Respondents & 534 & \\
\hline
\end{tabular}

\subsection{Recognition of Filial Piety Culture}

More than half of the preschool education students believe that they have clear understanding or relatively clear understanding of the traditional filial piety culture $(62.73 \%)$, and $37.26 \%$ of them think they know little about it. However, the majority of them believe that it is very necessary $(57.68 \%)$ or necessary $(36.14 \%)$ to advocate the filial piety culture.

\subsection{Realization of Filial Piety Culture Cultivation Channels}

The following data (see Chart 2) show that the preschool education students think that family influence is the most important way to understand the culture of filial piety and respect for the elderly (54.31\%), while the social environment and school education also exert some impact. On the matter of the ways to make more people understand and accept the Chinese traditional filial piety culture, the first two choices that most preschool education students made are to make use of all kinds of media to 
Study on the Inheritance and Future-Generation Transmission of Filial Piety and Respect for the Elderly Culture of the New Generation of Preschool Education Undergraduates in Shanghai

increase publicity $(84.83 \%)$ and to promote the festival tradition $(82.96 \%)$.

Table2: Undergraduates' suggestions on promoting Chinese traditional culture of filial piety and respect for the elderly in society

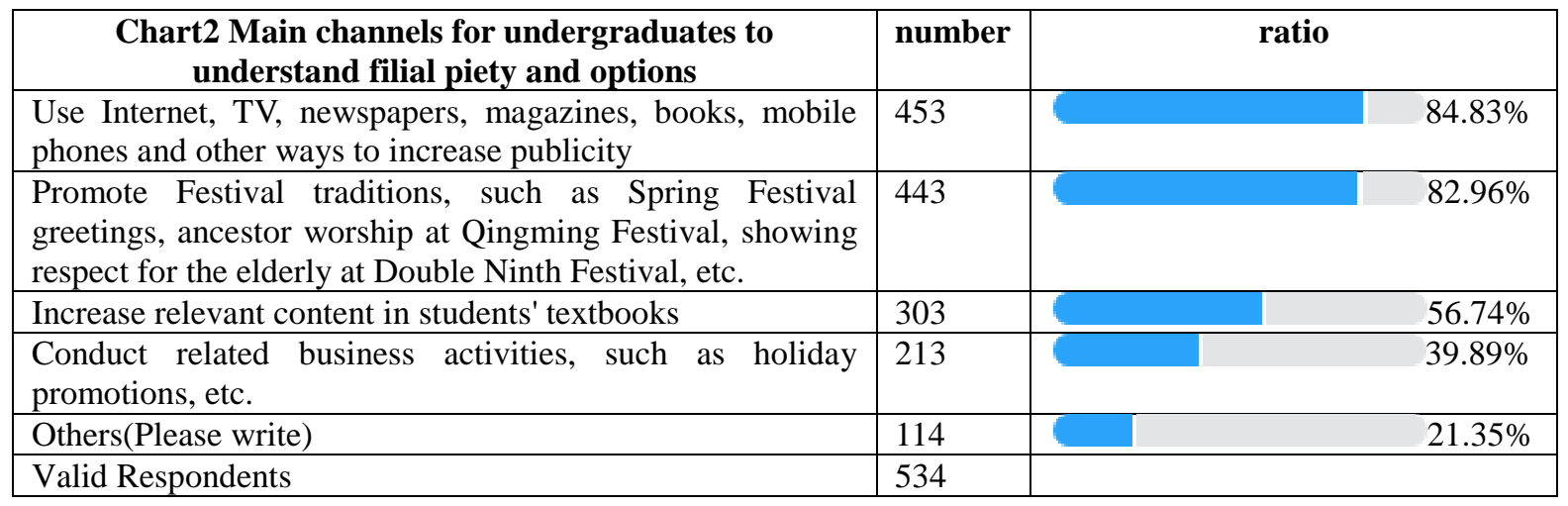

\subsection{Family's Influence on Filial Piety Culture Understanding}

Harmonious relationship between parents and children is a prerequisite for children to accept parental guidance. From the results of the survey, the vast majority of students have a good relationship with their parents (93.64\%), and in their daily life, parents and other elders have always or often taught them filial piety and respect for the elders $(85.27 \%)$.

Table3: Undergraduates' Understanding of the Performance of Filial Piety and Respect for the Elderly

\begin{tabular}{|l|l|c|}
\hline \multicolumn{1}{|c|}{ options } & number & ratio \\
\hline $\begin{array}{l}\text { Work hard to provide economic support for parents in } \\
\text { the future }\end{array}$ & 371 & $69.48 \%$ \\
\hline Obedient to parents & 223 & $41.76 \%$ \\
\hline $\begin{array}{l}\text { Care about parents' mental, psychological, emotional } \\
\text { and health status }\end{array}$ & 485 & $90.82 \%$ \\
\hline Respect for the old people of the whole society & 385 & $72.1 \%$ \\
\hline Valid Respondents & 534 & \\
\hline
\end{tabular}

\subsection{Preschool Education Students' Intention to Inherit and Pass on the Filial Piety Culture to} Children (Their Future Education Objects)

3.6.1. Identity Recognition as a Future Preschool Education Teacher whose Words and Deeds have Great Influence on their Students

The vast majority of preschool education college students (91.57\%) agree that it is necessary for them to set an example of practicing filial piety and respect for the elderly in daily life. However, there are a small number of them who suppose that it is not very necessary or absolutely unnecessary (8.42\%).

\subsubsection{Understanding of the Status Quo of Children Loving and Respecting Elders}

The new generation of preschool education students suppose that current preschool children have some awareness of loving and respecting elders $(66.85 \%)$, while one third of them think that there is no or a lack of such kind of awareness.

Table4: College Students' analysis on the reasons for the lack of awareness of filial piety and respect for elderly in the society

\begin{tabular}{|c|c|c|}
\hline option & number & ratio \\
\hline Lack of demonstration and education in family & 446 & $83.52 \%$ \\
\hline No or few related courses and activities in kindergartens & 338 & $63.3 \%$ \\
\hline exposure to unhealthy social phenomena & 339 & $63.48 \%$ \\
\hline Lack of correct guidance in the media & 343 & $64.23 \%$ \\
\hline others (Please write out) & 10 & $1.87 \%$ \\
\hline Valid Respondents & 534 & \\
\hline
\end{tabular}

\subsection{Recognition of the Necessity of Children's Filial Piety and Respect for the Elderly Education}

The vast majority of preschool education students (98.87\%) believe that it is necessary for children to obtain filial piety and respect for the elderly education and kindergartens play a very important role in 
Study on the Inheritance and Future-Generation Transmission of Filial Piety and Respect for the Elderly Culture of the New Generation of Preschool Education Undergraduates in Shanghai

the education $(99.44 \%)$.

\subsubsection{Recognition of the Educational Ways of Filial Piety and Respect for the Elderly}

Preschool education students believe that the most important way to educate children to love parents and respect elders (see Table 5) is regional activities (85.96\%), and others include collective teaching activities, game activities and random education activities.

Table5: Undergraduates' recognition of the most effective educational ways of filial piety and respect for elderly

\begin{tabular}{|l|l|l|}
\hline \multicolumn{1}{|c|}{ option } & \multicolumn{1}{c|}{ number } & ratio \\
\hline Collective teaching activities & 372 & $69.66 \%$ \\
\hline Regional activities & 459 & $85.96 \%$ \\
\hline Game activities & 332 & $62.17 \%$ \\
\hline Random Education Activities & 201 & $37.64 \%$ \\
\hline others (Please write out) & 2 & $0.37 \%$ \\
\hline Valid Respondents & 534 & \\
\hline
\end{tabular}

3.7.2. Recognition of the Effects of Filial Piety and Respect for the Elderly Education in Kindergartens

Most of the preschool education students (91.39\%) believe that the kindergartens' filial piety and respect for the elderly education exerts certain effects, but nearly one-tenth of the respondents $(8.61 \%)$ think that the effect is not notable. The principal cause of this unsatisfactory situation is that parents have no needs or motivations $(78.46 \%)$, followed by the facts that kindergartens do not pay enough attention to it, teachers do not get related training, and children are not interested in it.

Table6: Undergraduates' suggestions on improvement of filial piety and respect for elderly education in kindergarten

\begin{tabular}{|c|c|c|}
\hline option & number & ratio \\
\hline $\begin{array}{l}\text { Education goals (including general goals and age goals } \\
\text { and corresponding gradation structure) }\end{array}$ & 274 & $51.31 \%$ \\
\hline $\begin{array}{l}\text { Education content (corresponding cognition, emotion and } \\
\text { behavior) }\end{array}$ & 521 & $97.57 \%$ \\
\hline $\begin{array}{l}\text { Education methods (such as verbal guidance, situational } \\
\text { teaching or methods mainly based on direct perception) }\end{array}$ & 337 & $63.11 \%$ \\
\hline $\begin{array}{l}\text { Education approaches (including specialized or random } \\
\text { educational activities, kindergarten-family cooperation } \\
\text { and social education) }\end{array}$ & 305 & $57.12 \%$ \\
\hline others (Please write out) & 3 & $0.56 \%$ \\
\hline Valid Respondents & 534 & \\
\hline
\end{tabular}

\subsection{Envisage of Kindergarten Filial Piety and Respect for Elderly Education in the Future}

Almost all preschool education students (99.44\%) believe that they will consciously integrate filial piety and respect for elderly education in their future teaching. When asked about the most desired support for such education, the first is the active participation of the parents $(97.19 \%)$, followed by the provision of supporting courses or activities programs (54.31\%), the special training and funding, and in other options, some mentioned the permission of going out of kindergarten to carry out collective social practice, such as going to the nursing homes.

Table7: Expected support of college students for filial piety education in kindergartens in the future

\begin{tabular}{|c|c|c|}
\hline option & number & ratio \\
\hline Parents' active participation & 519 & $97.19 \%$ \\
\hline Related training & 199 & $37.27 \%$ \\
\hline Funding for special activities & 196 & $36.7 \%$ \\
\hline Supporting courses or activity programs & 290 & $54.31 \%$ \\
\hline Others (Please write out) & 7 & $1.31 \%$ \\
\hline Valid Respondents & 534 & \\
\hline
\end{tabular}

\subsection{Analysis of Individual Interview Results}

\subsubsection{Understanding of the Connotation of Filial Piety and Respect for the Elderly Culture}

- What Pops into your Head when We Talk about the Filial Piety and Respect for Elderly Culture?

International Journal on Studies in English Language and Literature (IJSELL) 
When we talk about the filial piety and respect for the elderly culture, the preschool education students often recall their parents' care for grandparents, or think of following their parents' instructions or sense of responsibility for parents and elders; it may also remind them of such harmonious pictures as a big family of three generations sitting together in a circle or the ethnic concepts implied in such ancient sayings "Filial Piety is the foundation of all virtues".

For example, one student said: "as an old saying goes, filial piety is fundamental, which is quite an important personal quality and plays a significant role in traditional culture. We would give our seats to the elders, regardless they are our grandparents, parents or even the old people we do not know on the bus."

Another student said: "when it comes to the filial piety, I think of my mother and an event with deep impression in childhood. My mom was very strict with me and quite good to my grandparents. When I was 6 years old, for I grabbed the TV remote with my grandparents, my mom asked me to kneel at the door in winter with thin clothing.

- Some People Say that Filial Piety and Respect for the Elderly is Out of Date and Should Not be Advocated Today. What's Your Opinion?

All 10 interviewees did not approve of it. On the contrary, they believe that filial piety and respect for elders would never be out of date. It is traditional virtue, foundation and responsibility. At the same time, filial piety can also keep pace with the times.

One student said: "Parents raise you and you should practice filial piety. That is the eternal responsibility for a human and responsibility is not going to be outdated."

Another student said: "There is supposed to be no such kind of proposal in the first place. Filial piety and respect for the elderly have always been traditional virtues in any time, for any people whether Chinese or not. After all, they are elders. We should not forget the tradition of loving and respecting the elderly when society is developing and lives are becoming better."

- Some People Think that the Most Important Part of Filial Piety and Respect for the Elderly Culture is the Obedience to Parents. What is Your Opinion?

All 10 interviewees believed that filial piety does not mean complete obedience and they should have their own viewpoints. Communication is the way to deal with conflicts.

One student said that: "Filial piety does not mean $100 \%$ obedience to their parents. After all, due to the differences in culture and growing environment, children and parents will be controversial about some things such as the style of clothes, the direction of life etc. but they can communicate. No parents would deliberately act against their children. Many parents are worried that their children will not communicate.

Another student said: "Obedience does not mean 100\% satisfying the elders' demands. We need to have our own judgment. If their demands are reasonable, we should be obedient, but in some cases, such as buying dietary supplement, we cannot simply say yes, we have to deal with the issue based on the actual condition in proper ways."

- At present, our country is advocating innovation. Is it necessary for the filial piety and respect for the elderly culture to innovate? What can we do?

Half of the interviewees think that it is necessary to innovate, but the innovation should not be limited to festival activities, but from daily details. Some students do not accept the concept of innovation of filial piety and respect for the elderly culture, and suppose that it is proper to say it requires update and keeping pace with the times.

For instance, one student said: "Innovation is necessary. There is definitely something outdated in the old things. Keep the positive essence and discard the negative dross. Sometimes the elders may be unable to remember, we can film it, which is also a kind of innovation. When we talk about respecting parents and elders, in the past, whatever they said were considered right, but nowadays, the young people have their own ideas, so communication is very important."

Another student said: "It needs to improve with times development. If the elders of your family are 
old-fashioned and stubborn, demanding unconditional obedience, you can try to change it tactfully. Some parents want to leave savings to their children. I would like them to spend it and take good care of themselves. I hope that my parents could lead an easy and stable life rather than be mentally and physically spent.

\subsubsection{Factors influencing the cognition of filial piety and respect for elderly culture}

- What is the main influence of your parents on your understanding of filial piety and respect for the elderly culture?

All 10 interviewees mentioned the positive influence of parents (as a role model), especially mothers, on their recognition of filial piety and respect for elders, and some of them said the impact is quite great. They gave us some daily details in life to illustrate:"Dad visits grandma and grandpa every week (an hour's drive away). Cook delicious food and take it to them. Visit is very frequent. Grandparents are not strong and surefooted as before, so dad often buys some articles for daily use and takes to them."

"Both my father and mother are very filial to grandparents. I live with my mother and learn more from her. Mom visits her parents every week to help wash dishes and cook meals. She also pays attention to how the elderly lead a healthy life, and teaches grandparents step by step. After the Spring Festival dinner, she would ask me to wash dishes. With my growing up, my behavior also affects my younger sister.

There is a good atmosphere in the family. "

- What is the main influence of school (from kindergarten to university) on your understanding of filial piety and respect for the elderly culture?

All 10 interviewees think that from kindergarten to university, school education does have an impact on it. However, from kindergarten and primary school to middle school and high school then to college and university, the impact is diminishing. Many interviewees still remember that in kindergarten and primary school, teachers arranged homework to ask them to give a massage to their parents' back, help parents wash feet and write compositions of these activities.

"In primary school, teachers asked us to help the elders relax by slapping their backs gently and having their feet washed when we went back home. Mom always told me to do these things from my heart. When we were doing exercises between classes, our school would play the video of Standards for Being a Good Student and Child and Three Character Classic. In a Double Ninth Festival activity, our head teacher gave each of us a piece of paper writing 'Loving and respecting your parents, elders and older siblings is fundamental as a human'. I still keep the paper and appreciate the value of the words better and better with my growing up."

\subsubsection{The Influence of the Identity as Preschool Education Students on their Filial Piety Practice And Future Filial Piety Education}

- Does the identity of preschool education student affect your behavior, especially filial piety and respecting the elderly? Why?

All interviewees acknowledged that the identity of preschool education student had an impact on their filial piety practice; however, some of them pointed out that teachers at any education level should be filial and respect the elderly.

"No matter at what education stage, teachers should be moral people in the first place. Filial piety is traditional culture, and we should develop and promote it."

"As teachers, we must set a good example. We do not have such kind of kindergarten in China so far. Existing ones are basically a combination of Chinese and western culture and emphasizes English training. We need lead children to learn the meaning of love at the preschool stage, help them become people with love and then when they grow up, they can build a mutual-loving society in the future."

- Will you integrate filial piety and respect for the elderly education in your future teaching? How would you do it?

All interviewees gave affirmative answers. They also put forward a number of implementation ideas, 
such as incidental education through life activities and games, to remind young children to experience the hard work of their elders; guiding children to express their love for elders in language, arts or handwork classes and so on.

"Instruction and games in daily life is the most common way and it is better to integrate education into everyday life. Filial piety education has to start from very young age. When people are grown up, it is hard to change. It is a lifelong matter, and the kindergarten is the place where it buds."

\section{RESEARCH CONCLUSIONS AND POLICY RECOMMENDATIONS}

\subsection{Research Conclusions}

1. The new generation of preschool education students in Shanghai actively recognizes their role as inheritor of traditional culture, including filial piety and respect for the elderly.

The vast majority of the preschool education students in Shanghai believe that filial piety is an important part of Chinese traditional culture with a constant value. For a human being, it is one of the most essential virtues, and worth for promotion. This is consistent with previous research findings, that is, contemporary college students basically agree with the value connotation of Chinese excellent traditional culture. [10]

In addition to the subtle and constant influence of family, the social environment (including media) is listed as an important way to understand the filial piety and respect for the elderly culture ahead of school education. Compared with the past, the new generation of preschool education students has much more diverse access to traditional culture. The influence of traditional media (including television, movies, and books) still remains with the use of the latest mobile smartphones, and the impact of new media (mainly micro-blog or blogs, instant chat tools such as WeChat or QQ) can't be underestimated.

2. The new generation of preschool education students in Shanghai regards it as their mission to inherit and pass on the culture to the pre-school children.

Based on the recognition of traditional culture, the new generation of preschool education students in Shanghai regards it as their mission to inherit and pass on the culture to the pre-school children. First of all, they fully realize their identity as a future kindergarten teacher, with the thoughts that they should practice filial piety and respect the elderly in daily life. They also recognize the current problems in preschool education, that is, there is not enough positive guidance and demonstration in families, schools and society, which leads to the lack of children's awareness of filial piety and respect for the elderly. Second, they recognize the role that the kindergarten plays in filial piety and respect for the elderly. Finally, they propose their own ideas and suggestions on how to carry out the education of filial piety and respect for the elderly in kindergartens, such as cooperation with parents, organic integration through festival activities, starting from education content and more childrencentered regional activities as the main implementation way.

\subsection{Policy recommendations}

\subsubsection{Establish a Family-Based Social Ethics System of Filial Piety and Respect for the Elderly}

This paper proposes establishing a family-based filial piety and respect for the elderly social ethics system, and making the related units of district and county (such as civil affairs department, women's federation and other departments) and even the community residents' committees fully take the responsibility of guidance and support. Whether in elementary education or high education system, getting closer connection with family and more support from parents should be paid more attention in any school work

\subsubsection{Give Full Play to the Educational Functions of Schools at all Levels}

The research results may serve as a good reference for the revision and improvement of preschool education professional training programs. At the college stage, self-directed learning is advocated, but colleges and their departments can also consciously provide guidance, for example, they can incorporate related contents into ideological and political lessons, and general education classes, or use micro courses to help them learn and think about the basic connotation and times requirements of the filial piety and respect for the elderly culture; or take out-of-school filial piety and respect for the 
elderly activities into practice credit counting system.

\subsubsection{Create Filial Piety and Respect for the Elderly Social Atmosphere through Various Kinds of Media}

Holidays are a good chance of family reunion to enhance family ties, as well as an effective carrier for cultural transmission. Holiday activities such as Spring Festival greetings, Qingming ancestors worship, Double Ninth respect for the elderly, and so on are good opportunities to promote the filial piety and respect for the elderly culture, which proves to be the successful experience of kindergarten to carry out traditional culture education and also one of the ways advocated by preschool education students to understand and accept Chinese traditional filial piety and respect for the elderly culture. During the holiday seasons, the media should help to promote filial piety and respect for the elderly culture from perspectives of public opinion guidance and public cultural dissemination.

\subsubsection{Emphasize the Institutionalization of Filial Piety and Respect for the Elderly}

Filial piety and respect for the elderly is supposed to be a kind of personal moral cultivation, but under certain institutional systems, people who well practice it can also get positive economic feedback and social evaluation.

Finally, it is necessary to point out that "when the country is bountiful, its citizens are civil; when people have met their basic wants, they are scrupulous." Currently, the problem of food and clothing has been solved in most parts of China, but due to the deep memory of the past physical deficiency and a variety of existing social problems, the whole social community lack sense of security in issues concerning their basic interests, such as housing, medical care, education, elderly care, etc. Thus there is widespread anxiety in the society. If the problems of citizens' basic needs cannot be solved, it is difficult to make a difference in moral cultivation. The government has a direct responsibility for the issues of basic support and cannot shirk all responsibility to the family. It is believed that with the improvement of the overall national strength, the government will be more and more capable of solving these problems with input increase. Additionally, apart from economic interdependence, family members are likely to create a much healthier family relationship.

\section{REFERENCES}

[1] Luan Yinzhi. "Shanghai has Entered in-depth Aging Stage." Liberation Daily 23 April 2015.

[2] Zhao Li. "Theoretical Thoughts on University Students Inheriting Chinese Filial Piety Culture." Journal of Lanzhou Institute of Education 2(2013):40-43.

[3] Tang Yijie. "The Significanse of Filial Piety as Family Ethnics." Journal of Peking University (Philosophy and Social Sciences) 4(2009):11-13.

[4] Jin Hongqing. "Festival Culture and Festival Curriculum Development in Kindergartens." Preschool Education Studies 3(2007): 44-46.

[5] Yuan Suling. "Enlightment of Singapore's Pro-family Policy." Chinese Women's Movement 2(2015):42-43+45.

[6] Cheng Weimin and Xiong Jiansheng. "Analysis on the Contemporary University Students' Recognition and Identity of Chinese Excellent Traditional Culture - based on the questionnaire survey of 700 students of more than 10 universities in China." Education Research and Experiments 4(2016):68-71+87.

Citation: Haiyan Hao. Study on the Inheritance and Future-Generation Transmission of Filial Piety and Respect for the Elderly Culture of the New Generation of Preschool Education Undergraduates in Shanghai. "International Journal on Studies in English Language and Literature (IJSELL), vol 7, no. 11, 2019, pp. 1-10. doi: http://dx.doi.org/10.20431/2347-3134.0711001.

Copyright: (C) 2019 Authors. This is an open-access article distributed under the terms of the Creative Commons Attribution License, which permits unrestricted use, distribution, and reproduction in any medium, provided the original author and source are credited. 